\title{
PASAR BERKONSEP “TOUCH AND GO” DI TEPI SUNGAI CISADANE
}

\author{
Febriana $^{1)}$, Agustinus Sutanto ${ }^{2)}$ \\ 1)Program Studi S1 Arsitektur, Fakultas Teknik, Universitas Tarumanagara, fjoesman@outlook.com \\ 2)Program Studi S1 Arsitektur, Fakultas Teknik, Universitas Tarumanagara, gak.architects@gmail.com
}

\begin{abstract}
Abstrak
Milenial menentukan wajah Indonesia ke depan. Menurut data Badan Perencanaan Pembangunan Nasional (Bappenas) ada 63 juta milenial atau penduduk usia $20-35$ tahun. Mereka ada di usia produktif. Yang perlu diperhatikan adalah perlunya mendorong mereka agar menjadi roda penggerak ekonomi Indonesia. Kota Lama Tangerang adalah sebutan untuk sebuah kawasan pecinan yang merupakan cikal bakal berkembangnya Kota Tangerang. Namun karena gencarnya pembangunan di kawasan ini dan sekitarnya membuat kawasan ini kehilangan sisi historisnya. Pemkot Tangerang sedang berusaha menetapkan kawasan ini menjadi kawasan wisata budaya. Keberadaan pasar tradisional di kawasan ini bukan semata untuk urusan ekonomi, namun mencakup isi ruang dan relasi sosial, warisan dan budaya. Kondisi Pasar Tradisional Kisamaun saat ini sangat memprihatinkan dalam hal kebersihan dan kenyamanan, serta sarana dan prasarana yang sudah sangat tidak layak, dan mengambil kawasan yang tidak seharusnya (didepan bangunan yang seharusnya dilindungi). Walaupun demikian, minat masyarakat sekitar tetap tidak berkurang meskipun keadaan pasar sudah tidak memungkinkan untuk dikunjungi. Harga barang yang murah dan bersaing yang ditawarkan dalam lingkup pasar tradisional menjadi pilihan dari sebagian masyarakat. Oleh karena keberadaan Pasar Tradisional Kisamaun ini sangat penting dalam perkembangan perekonomian kota dan kawasan historis ini, maka perlu dilakukan Redesain Pasar Tradisional Kisamaun ini. Dengan tidak menghilangkan bagian - bagian yang menjadi ciri khas daerah pecinan ini, dengan tema Arsitektur Vernakular China. Pendekatan vernakular pecinan digunakan dalam desain pasar wisata ini, dengan tujuan menggali eksotisme lokalitas budaya yang digabung dengan selera kontemporer masa kini, sehingga pasar ini dapat menjadi destinasi wisata.
\end{abstract}

Kata kunci: Ekonomi; Pasar Lama Tangerang; Pasar Tradisional; Redesign

\begin{abstract}
Millennials determine Indonesia's face in the future. According to data from the National Development Planning Agency (Bappenas) there are 63 million millennials or people aged 20 35 years. They are in productive age. What needs to be considered is the need to encourage them to become the driving force of the Indonesian economy. The Old City of Tangerang is the name for a Chinatown which is the forerunner of the development of the City of Tangerang. But because of the intense development in this region and its surroundings, this region has lost its historical side. Tangerang City Government is trying to establish this area as a cultural tourism area. The existence of traditional markets in this region is not solely for economic affairs, but includes the contents of space and social relations, heritage and culture. The current condition of the Traditional Market Kisamaun is very concerning in terms of cleanliness and comfort, as well as facilities and infrastructure that are already very improper, and take areas that are not supposed to (in front of buildings that should be protected). Nevertheless, the interest of the surrounding community still does not diminish even though the market situation is not possible to visit. The price of cheap and competitive goods offered in the traditional market environment is the choice of some people. Because the existence of the Kisamaun Traditional Market is very important in the economic development of this city and historical region, it is necessary to do this Kisamaun Traditional Market Redesign. By not eliminating the parts that characterize this Chinatown, with the theme Vernacular Architecture of China. The vernacular approach of Chinatown is used in the design of this tourist market, with the aim of exploring the exoticism of cultural locality combined with contemporary contemporary tastes, so that this market can become a tourist destination.
\end{abstract}




\section{PENDAhULUAN}

\section{Pengertian Pasar}

Pasar sebagai suatu bentuk pelayanan umum tempat terjadinya transaksi jual beli barang bagi masyarakat, merupakan salah satu cerminan perekonomian dan sosial budaya setiap komunitas di dunia ini. Seiring dengan perkembangan zaman, dari waktu ke waktu pasar mengalami evolusi bentuk tempat dan cara pengelolaannya, dari yang bersifat tradisional menjadi modern.

Pasar tradisional saat ini menjadi perhatian banyak pihak terutama setelah pemerintah mengagas program revitalisasi pasar tradisional. Program revitalisasi ini digagas untuk merespon masalah tahunan pasar tradisional di Indonesia, yang dilihat sebagai suatu tempat yang kumuh, kotor, becek, dan tidak terawat.

Pertumbuhan di sektor ritel memang masih terus tercatat tinggi, meskipun pertumbuhan tinggi tersebut hanya dialami oleh ritel modern, yang sangat mungkin merupakan kebalikan dari ritel tradisional, yang justru dalam beberapa kesempatan menyatakan sebagai bagian yang paling dirugikan akibat dari perkembangan yang terjadi saat ini di sektor ritel.

Penelitian yang dilakukan Sitompul pada tahun 2012 yang bertujuan untuk meningkatkan kinerja dan kualitas pasar, tapi pada kenyataannya tidak sesuai dengan program yang dicanangkan. Program revitalisasi tidak sepenuhnya optimal, akan tetapi menjadi penyebab pasar tradisional semakin sepi. (Ekomadyo \& Hidayatsyah,2012)

Adapun komposisi industri ritel Indonesia dalam perkembangan terakhir digambarkan dalam survey yang dilakukan oleh AC Nielsen dalam tahun 2004-2005, sebagaimana terlihat dalam tabel 1.

Tabel 1. Struktur Pengecer di Indonesia

\begin{tabular}{|c|c|c|}
\hline Sektor & 2004 & 2005 \\
\hline Toko Tradisional & 1.745 .589 & 1.787 .897 \\
\hline Convenience Store & 154 & 115 \\
\hline Supermarket & 6.560 & 7.606 \\
\hline - $\quad$ Sub-Supermarket & 956 & 1.141 \\
\hline - Minimarket & 5.604 & 6.456 \\
\hline Large Format Store & 90 & 107 \\
\hline - Hypermart & 68 & 83 \\
\hline - Warehouse clubs & 22 & 24 \\
\hline Total toko eceran & 1.752 .393 & 1.795 .725 \\
\hline \multicolumn{3}{|l|}{ Toko Obat } \\
\hline Traditional Drugstore & 17.699 & 16.663 \\
\hline Chain Drugstore & 218 & 245 \\
\hline Total Took Obat & 17.917 & 16.908 \\
\hline
\end{tabular}

Sumber: AC Nielsen, 2006

Data survey ini, memperlihatkan bahwa ritel modern sesungguhnya belum apa-apa, apabila dibandingkan secara kuantitas dengan ritel tradisional. Jumlah pelaku usaha di ritel tradisional jauh di atas jumlah pelaku usaha di ritel modern dengan selisih kuantitas yang sangat signifikan. Pasar tradisional diperkotaan akan segera punah (Cahyono, 2006:21).

Hingga tahun 2010, Pemerintah terlalu "memanjakan" ritel modern sehingga peritel modern menguasai pangsa penjualan eceran hingga $50 \%$. Jika sikap ini diteruskan maka pasar tradisional akan terus tergerus seperti terlihat pada tabel 2 berikut ini. 
Tabel 2. Persentase Kontribusi Omzet

\begin{tabular}{|c|c|c|}
\hline Tahun & Pasar Tradisional & Pasar Modern \\
\hline 2001 & 75,2 & 24,8 \\
\hline 2002 & 74,8 & 25,1 \\
\hline 2003 & 73,7 & 26,3 \\
\hline 2004 & 69,6 & 30,4 \\
\hline 2005 & 67,6 & 32,4 \\
\hline 2006 & 65,5 & 34,4 \\
\hline
\end{tabular}

Hasil penelitian AC Nielsen penjualan produk sehari - hari di pasar tradisional bisa mengalami penurunan lagi sebesar $2 \%$, ini menunjukkan pangsa pasar tradisional termakan ritel modern berformat minimarket.

Perkembangan lain yang sangat menonjol adalah bahwa ritel kini telah berubah fungsinya dari sekedar tempat menyalurkan produk ke konsumen, tetapi juga menjadi industri tersendiri. Perspektif baru terhadap industri ritel kini justru muncul dari mata produsen. Ritel kini dianggap menjadi tempat yang strategis, untuk memasarkan barangnya secara tepat waktu, lokasi dan konsumen.

Tetapi sebagaimana ditulis di awal, kondisi ini di sisi lain juga membawa dampak yang negatif yakni tersingkirnya pelaku usaha di ritel tradisional yang umumnya merupakan pelaku usaha ritel kecil. Padahal jumlah usaha ini termasuk yang paling banyak ditekuni oleh bangsa Indonesia. Gambaran terdahulu memperlihatkan bahwa $45 \%$ dari usaha yang ditekuni pelaku usaha Indonesia, merupakan usaha dalam bidang eceran ini.

Kecenderungan ritel yang tampaknya merupakan sebuah keniscayaan, berupa keunggulan bersaing dari pelaku usaha ritel yang terwujud dalam bentuk kenyamanan, keamanan, kemudahan berbelanja, memang sangat mudah diwujudkan oleh pelaku usaha dengan kemampuan modal besar. Sebaliknya untuk usaha kecil, tanpa bantuan Pemerintah maka hal tersebut hanya menjadi harapan belaka. Tidaklah mengherankan ketika liberalisasi ritel terjadi, maka serbuan peritel bermodal besar untuk menjaring pasar dengan ceruk yang cenderung mengarah kepada tuntutan perkembangan ritel di atas, menjadi tidak tertahankan.

Kalau dilihat dari sisi kenyamanan, membeli barang di online lebih menyenangkan karena pembeli tinggal menelepon atau memencet langsung datang pesanannya. Dibanding jika kita harus bersusah payah ke pasar tradisional yang harus berjalan ke "medan perang".

Untuk menarik konsumen, PD Pasar Kota Tangerang selaku perusahaan daerah untuk mengatur pelayanan umum dalam bidang pengelolaan pasar, juga akan menyiapkan pasar tradisional dengan konsep yang lebih atraktif. Titien Mulyati, Dirut mengatakan pihaknya berencana menambahkan fasilitas baru untuk mengangkat jumlah pengunjung. "Kegiatan yang menunjang di masyarakat sekitarnya, itu beberapa hal yang coba dipayungi dari Raperda." Selain itu, pihaknya terus mengupayakan penguatan distribusi dari sisi perusahaan termasuk untuk menunjang program pemerintah, seperti menjaga stabilisasi harga. (pdpasarkotatangerang.co.id)

Pada umumnya setiap pembeli selalu menginginkan barang-barang yang berkualitas tinggi dengan harga yang murah dan suasana berbelanja yang nyaman, bersih dan tersedia berbagai fasilitas yang dibutuhkan pembeli seperti transaksi elektronik (ATM dan kartu kredit) dan tersedianya tempat parkir yang luas. Kesemua fasilitas tersebut tentunya terdapat di pasar modern. Memuaskan pembeli adalah merupakan kunci sukses dalam melaksanakan bisnis perdagangan. Berbagai tanggapan dari pelanggan perlu diterima sebagai masukan yang berguna bagai pemgembangan suatu perdagangan, oleh karena itu pedagang dalam mencapai tujuannya tersebut harus mengetahui apa yang diinginkan dan yang dibutuhkan oleh pembelinya. Namun tidaklah mudah bagi pedagang untuk mengenal watak dan prilaku dari pembelinya, karena bisa jadi apa yang diungkapkan itu bertolak belakang dengan sebenarnya. 


\section{Tentang Pasar Lama, Tangerang}

Tangerang adalah sebuah kota yang terletak di Provinsi Banten, Indonesia, tepat di sebelah barat kota Jakarta, serta dikelilingi oleh Kabupaten Tangerang di sebelah utara dan barat. Tangerang merupakan kota terbesar di Provinsi Banten serta ketiga terbesar di kawasan perkotaan Jabotabek setelah Jakarta. Kota Tangerang memiliki daerah dimana daerah tersebut ramai dengan penduduk keturunan Tionghoa Tangerang. Daerah tersebut diberi nama Petak Sembilan, tepi sekarang sudah berubah nama menjadi Pasar Lama.

Kota Tangerang yang tidak banyak memiliki potensi wisata alami seperti di daerah Jawa Barat maka, pusat-pusat sejarah dan keramaian yang dikelola dan dikembangkan. Beberapa potensi wisata yang telah sudah teralisasi seperti wisata air Cisadane dan Situ Cipondoh. Wisata religi Masjid Pintu Seribu dan Kelenteng Boen Tek Bio. Wisata rekreasi Taman tematik Potret, Taman Ekspresi, Taman Bambu dan Taman Pisang. Wisata sejarah Rumah Burung, termasuk wisata kuliner di kawasan Pasar Lama.

Pasar lama merupakan daerah yang sering dikunjungi penduduk sekitar, orang yang berjualan maupun pembeli merupakan keturunan Tionghoa Tangerang. Maka dari itu pasar lama dikenal dengan tempat yang sangat strategis dan sangat lengkap. Disinipun terdapat klenteng Boen Tek Bio, Viara Padum, Lithan Bio, museum Heritage, sungai Ciasadane, stasiun Tangerang, masjid Jami Kalipasir dan pertokoan lainnya yang sudah turun temurun berjalan serta penjual makanan khas yang berbeda dengan kota lainnya yaitu makanan khas peranakan.

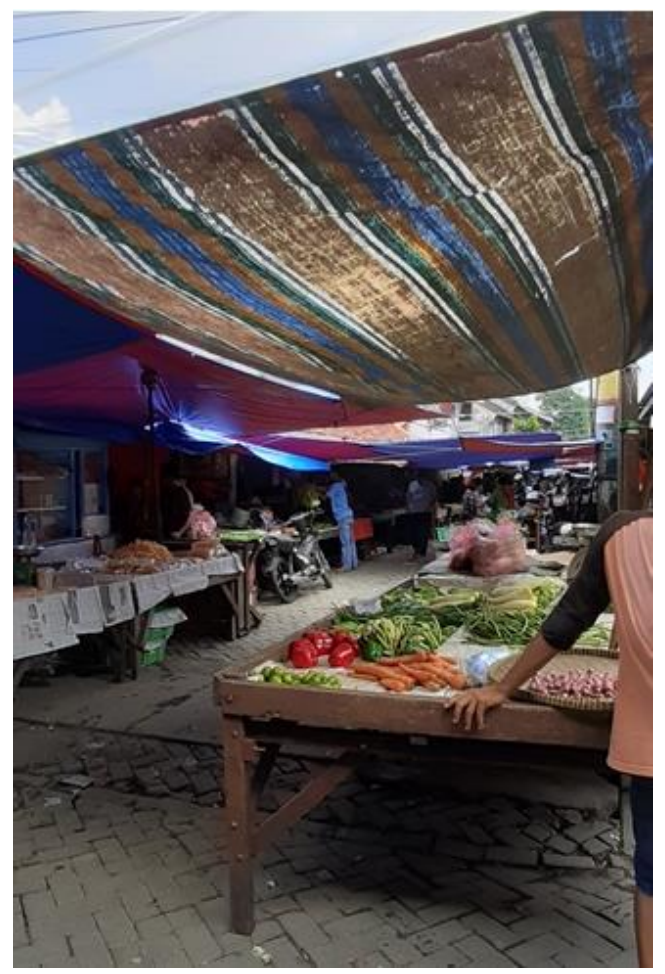

Gambar 1. Keadaan Pasar Kisamaun Sumber: Penulis, 2019

Pasar Lama yang di resmikan mejadi tempat wisata kuliner dimulai pada tahun 2012 dengan nama Kawasan Kuliner Pasar Lama. Berlokasi di Jl. Kisamaun, Sukasari Kec. Tangerang, Kota Tangerang, keberadaan pasar ini terbentuk dari sejarah yang dahulunya merupakan pusat perdagangan tertua di kota Tangerang dan cagar budaya, karena kawasan ini sangat kental dengan akulturasi budaya seperti Cina, Betawi, Eropa, dan Sunda. Setelah itu, berkembanglah kawasan ini menjadi kawasan kulner karena para pedagang makanan yang mulai memenuhi area tersebut. Kuliner Pasar Lama banyak menyajikan jenis makanan dan jajanan khas akulturasi seperti, Asinan Lan Jin, 2 Bubur Kepiting Hokie, khas Tangerang seperti Laksa Tangerang, Siomay 
Benteng dan ada beberapa jenis kulinernya yang sudah dikenal sebagai kuliner khas pasar lama karena pedangang yang sudah bertahun-tahun berjualan dan resep masakan tersebut merupakan turunannya terdahulu. Tersedia juga jenis kuliner kafe dan restaurant dan masih banyak lagi yang bisa ditemukan jika ditelusuri seluruh kawasan kuliner ini. Penjual kuliner di Kawasan Pasar Lama kebanyakan tidak membuka cabang di daerah atau tempat lain, sehingga kuliner tersebut hanya bisa ditemukan di kawasan ini. Selain kulinernya yang legenda dan beragam, tempat pada kawasan ini pun memiliki nilai sejarah.

\section{Pasar Tradisional dan Millennial}

Pasar tradisional bagi Millennial mungkin menjadi tempat yang tidak menarik.

Generasi Millennial dilahirkan di tengah era transisi dan dihadapkan pada kemajuan teknologi informasi, generasi Millennial memiliki karakteristik dan daya tariknya sendiri. Berbeda dengan generasi sebelumnya, generasi Millennial cenderung mementingkan kecepatan, kepraktisan, dan fleksibilitas. Millennial mengutamakan kecanggihan teknologi perbankan seperti e-banking dan online market dalam melakukan kegiatan jual beli. Permasalahan seperti penyusunan produk yang tidak baik, lingkungan yang lembab, tidak nyaman, kotor dan penjual yang berjualan di pinggiran kios karena membuat jalanan menjadi sempit dan macet. Kualitas fisik lingkungan dan kualitas proses perlu mendapatkan perhatian yang lebih jauh oleh pengelola pasar untuk melayani konsumen milenial. Tapi ada juga yang masih menyukai pasar tradisional karena harga yang lebih murah, sudah ada ikatan emosional dengan penjual karena sudah kenal dan sering berinteraksi. Inilah yang menjadi pertimbangan dalam mendesain pasar tradisional ini. Kegiatan perancangan ini sangat memperhatikan kenyamanan pengunjung, yaitu para pembeli dan penjual.

\section{KAJIAN LITERATUR}

Arti pasar dapat diartikan sebagai tempat bertemunya pembeli dan penjual. Meski begitu, definisi pasar secara umum dapat diartikan lebih luas berdasarkan teori ekonomi yang berlaku. Ada banyak juga jenis-jenis pasar yang ada dilihat dari strukturnya.

Ciri-ciri pasar antara lain adalah ada barang dan jasa yang diperjualbelikan, terjadi transaksi jual beli adanya proses permintaan atau tawar menawar serta terjadi interaksi antara penjual dan pembeli. Dalam pasar tentu ada penjual dan pembeli atau disebut konsumen.

Arti Pasar Menurut KBBI

Pengertian pasar menurut KBBI (Kamus Besar Bahasa Indonesia) adalah tempat orang berjual beli. Definisi lainnya menurut KBBI, pasar adalah kekuatan penawaran dan permintaan, tempat penjual yang ingin menukar barang atau jasa dengan uang dan pembeli yang ingin menukar uang dengan barang atau jasa.

Pengertian pasar menurut Simamora adalah sekumpulan orang yang memiliki kebutuhan dan keinginan terhadap produk tertentu, memiliki kemampuan dan kemauan untuk membeli produk tersebut dan memiliki kesempatan untuk memutuskan membeli sebuah produk.

Syarat - syarat terjadinya pasar

Bagaimana suatu tempat dapat dikatakan sebagai pasar?

Syarat - syaratnya adalah :

a. Ada tempat untuk berniaga

b. Ada barang dan jasa yang akan diperdagangkan

c. Terdapat penjual barang tertentu

d. Adanya pembeli barang

e. Adanya hubungan dalam transaksi jual beli

\section{Klasifikasi Pasar}

Pasar dikategorikan menjadi dua, yaitu Pasar Tradisional dan Pasar Modern. Pasar Tradisional

Pengertian pasar tradisional adalah suatu pasar dimana tempat tersebut merupakan tempat bertemunya para penjual dan pembeli serta terdapat transaksi jual beli secara langsung serta 
pada umumnya terjadi proses tawar-menawar.

Bentuk bangunan pasar tradisional biasa berupa los, kios-kios atau gerai, serta dasaran terbuka yang dibuka oleh para penjual ataupun dari pengelola pasar.

Barang-barang yang dijual oleh Pasar Tradisional biasanya merupakan barang kebutuhan seharihari, jasa dan lain-lain.

\section{Pasar Modern}

Pasar modern dan pasar tradisional tidak berbeda jauh, namun pasar modern tidak terdapat penjual dan pembeli yang bertransaksi secara langsung, melainkan konsumen atau pembeli melihat label harga yang terdapat dalam barang tersebut, berada dalam bangunan serta pelayanannya dilakukan secara mandiri atau swalayan dan dapat juga dilayani oleh pramuniaga. Barang yang dijual di pasar modern selain dari bahan makanan, terdapat juga barang lainnya yang dijual dan biasanya dapat bertahan lama.

Karakteristik Pasar Tradisional

- Dalam melakukan transaksi selalu terjadi proses tawar menawar dan interaksi sosial tak jarang terjadi hubungan baik dan saling mengenal antara penjual dan pembeli.

- Harga barang-barang yang dijual di pasar ini biasanya relatif murah dan sangat terjangkau

- Area pasar tradisional umumnya berada di tempat yang terbuka

- Di pasar ini tidak terdapat monopoli oleh satu produsen tertentu

- Harga barang, lokasi, dan cara pelayanan penjual merupakan faktor penentu besarnya penjualan

\section{METODE}

Metode yang digunakan dalam pembahasan adalah :

a. Tahap Pengumpulan Data

Pengumpulan Studi Literatur dan Preseden untuk mengetahui teori, spesifikasi dan karakteristik serta perkembangan pasar dari jaman dahulu sampai sekarang yang dapat dijadikan landasan dalam proses perancangan

b. Menganalisis data yang terkumpul dan mengamati kondisi lapangan kemudian diolah ke dalam konsepsi perancangan bangunan pasar

c. Proses Perancangan

4. DISKUSI DAN HASIL

a. Deskripsi Objek Perancangan

Redesain Pasar Tradisional adalah merancang kembali pasar yang bersifat tradisional menjadi lebih digital untuk mengikuti perkembangan jaman

b. Keunggulan Objek Perancangan

Pasar Kisamaun ini memiliki keunggulan bersaing yang tidak dimiliki secara langsung oleh pasar modern. Lokasi yang strategis dan hubungan antara penjual dan pembeli yang bagus serta harga yang terjangkau

c. Kajian Lokasi dan Tapak

Redesain Pasar Tradisional Kisamaun dengan pendekatan tema Arsitektural Vernakular Pecinan terletak di Jl. Kisamaun, Sukasari, Kec. Tangerang, Banten 15118 dengan luas tapak $3.336 \mathrm{~m}^{2}$

d. Pintu masuk tapak mengarah ke Barat, maka dari itu bukaan ke arah barat diminimalkan dan diberi shading agar terlindungi dari panas dan silau

e. Rencana penzoningan pada pasar dibagi 3, yaitu publik, semi-publik dan privat. Zona publik adalah tempat parkir dan ruang terbuka hijau, tempat berjualan dan restoran. Zona semipublik merupakan daerah ruang karyawan. Zona privat adalah area pemilik atau pengelola. Zona servis adalah area loading dan pool sampah sehingga ditaruh di tempat yang mudah diakses.

f. Sirkulasi menuju tapak bisa menggunakan kendaraan pribadi dan umum serta berjalan kaki. 
Terdapat stasiun Tangerang dekat tapak. Disediakan tempat parkir untuk ojek online di sebelah kanan bangunan.

g. Bentuk bangunan mengikuti daerah sekitar yang merupakan pecinan. Pemilihan ini untuk mempertahankan ciri khas daerah sekitar. Daerah ini terkenal dihuni etnis Cina Benteng yang nenek moyangnya berasal dari Cina Selatan. Desain bangunan dari Cina Selatan mengutamakan inner court, banyaknya bukaan dan desain yang memiliki teras. Proses desain pasar ini mengikuti konsep desain ini sehingga terbentuklah bangunan ini.

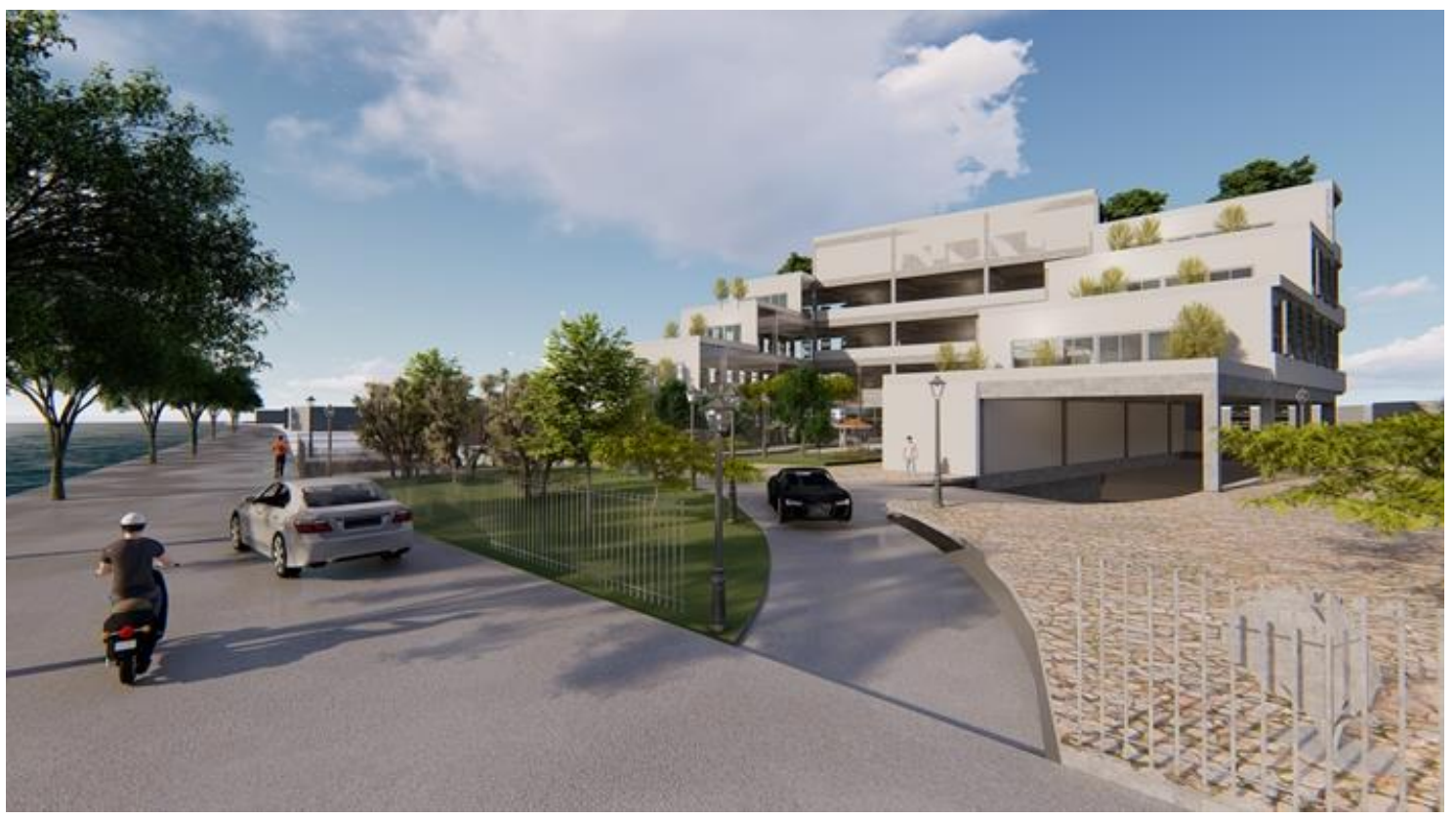

Gambar 2. Gedung Untarian Sumber: Kodoatie, 2005

\section{KESIMPULAN DAN SARAN}

Untuk mengembalikan dan mempertahankan citra Pasar Lama Tangerang dibutuhkan pengelolaan dan pemberdayaan yang baik pada pasar, salah satunya dilakukan dengan cara pembenahan Pasar Lama dengan cara menggabungkan konsep tradisional dengan konsep digital. Caranya dengan tetap mempertahankan suasana pasar tradisional (adanya tawar menawar, adanya komunikasi yang baik antara pedagang dan pembeli) dan dengan memodernkan pasar tradisional tersebut melalui cara merubah perilaku penjual maupun pembeli, mengelompokkan lokasi penjual (zoning), supaya lebih tertata, sistem pengolahan limbah dan sampah, serta penambahan fasilitas yang mendukung pasar sehingga mampu mewujudkan suasana yang bersih, nyaman, teratur dan aman bagi pengunjung yang berbelanja. Dengan begitu, diharapkan Pasar Lama Tangerang menjadi lebih baik dan menciptakan kenyamanan bagi pengunjung, sehingga Pasar Lama Tangerang semakin menarik dan ramai dikunjungi generasi Millennial.

Konsep "Touch and Go" yang dipilih berdasar perkembangan jaman sekarang yang hampir semua aktifitas dilakukan melalui handphone. Di pasar ini kasir ditiadakan. Sebaliknya diberi pintu masuk (portal untuk men-scan aplikasi di handphone pengunjung) jadi ketika pengunjung mengambil barang yang mau dibeli akan langsung di-input ke daftar belanja pengunjung yang bisa dilihat di handphone masing - masing.

Syarat operasional pasar harus diperhitungkan, seperti area bersih dan kotor, serta bagian persampahan agar rancangan yang dihasilkan dapat dipertanggungjawabkan secara keseluruhan. Luasan harus memperhatikan keadaan di lapangan, tidak hanya berdasarkan pada standar. 


\section{REFERENSI}

Andanweri, N. (2005). Jurnal Seni Rupa dan Desain oleh Fakultas Seni Rupa dan Desain Universitas Tarumanagara. Jakarta - Desember 2005. ISSN 1410-4903.

Asiapac Culture. (2003). Gateaway to Chinese Culture. Jakarta: Gramedia.

Belshaw, C. S. (1981). Tukar Menukar Tradisional dan Pasar Modern. Jakarta: Gramedia.

Handinoto. (2008). Perkembangan Bangunan Etnis Tionghoa di Indonesia (Akhir Abad ke 19 sampat tahun 1960-an). Surabaya:Universitas Petra.

Hanifan, L. (2002). Re-Desain Pasar Kota Purbalingga. https://dspace.uii.ac.id/handle/123456789/2615, diakses 26 Oktober, 2017.

Menjejak Titik Nol Tangerang, https://www.beritasatu.com/destinasi/60095-menjejak-titik-noltangerang.html. 11 Februari 2019

Peraturan Presiden Republik Indonesia Nomor 112 Tahun 2007 Tentang Penataan dan Pembinaan Pasar Tradisional, Pusat Perbelanjaan dan Toko Modern tentang Penataan Pasar Tradisional Pasal 1 dan Pasal 2.

Sejarah Pasar Lama Tangerang.

http://sejarahpasarlamatangerang.blogspot.com/2017/10/kelenteng-boen-tekbio.html\#more., diakses 2 Mei ,2019 